\title{
Chronic pain in adolescents: evaluation of a programme of interdisciplinary cognitive behaviour therapy
}

\author{
C Eccleston, P N Malleson, J Clinch, H Connell, C Sourbut
}

Arch Dis Child 2003;88:881-885

See end of article for authors' affiliations

......................

Correspondence to:

$\operatorname{Dr} C$ Eccleston, Pain

Management Unit,

University of Bath, Bath

BA2 7AY, UK;

c.eccleston@bath.ac.uk

Accepted

3 January 2003

\begin{abstract}
Aim: To determine the effectiveness of an interdisciplinary cognitive behavioural treatment for adolescents with chronic pain.

Methods: Fifty seven adolescents (mean age 14.28 years) with chronic pain and 57 accompanying adults underwent an interdisciplinary three week residential programme of group cognitive behavioural therapy. Mean chronicity of pain was 4.02 years; $75 \%$ were absent from full time education (mean absence 17 months).

Results: Post-treatment adolescents reported significant improvements for self report of disability (mean difference 3.37 (95\% Cl 0.65 to 6.09)), physical function (mean difference timed walk of 2.61 seconds (1.02 to 4.2 ) and sit to stand of 3.22 per minute $(0.79$ to 5.65$)$ ). At three months post-treatment adolescents maintained physical improvements and reduced anxiety (mean difference 1.7 (0.72 to 2.67)), disability (mean difference 4.3 (1.44 to 7.17)), and somatic awareness (mean difference 4.43 (1.53 to 7.33$)$ ). Following treatment adults reported significant improvement in their report of adolescent disability (mean difference 4.43 (2.17 to 6.7)), adult anxiety (mean difference 1.73 (0.54 to 2.92)), depression (mean difference $1.16(0.34$ to 1.98)), and parental stress (mean difference 10.81 (2.91 to 18.78$)$ ). At three months significant improvements were maintained. At three months $64 \%$ improved school attendance; $40 \%$ had returned to full time education.

Conclusions: Interdisciplinary cognitive behavioural pain management (with family involvement) is a promising approach to the management of pain, pain related distress, and disability.
\end{abstract}

C hildren and adolescents frequently experience and report pain. ${ }^{12}$ Up to $25 \%$ report persistent or recurrent tress and disability ${ }^{4}$ Treatment is frequently unsatisfactory to patients, families, and physicians.

We have suggested that the optimal treatment regime for these patients may be interdisciplinary cognitive behavioural therapy (ICBT), with parent involvement, that focuses on pain management and rehabilitation to normal activity. ${ }^{5}$ There is good evidence for the effectiveness of this approach with adults with chronic pain, ${ }^{6}$ and a strong evidence base for psychological therapies for related symptoms such as depression and anxiety. ${ }^{78}$ The evidence base, however, for this approach with children and adolescents is limited. In a recent (Cochrane) systematic review of all RCTs, we found very strong evidence for the effectiveness of psychological treatments in reducing the pain of chronic and recurrent headache," and promising evidence also for recurrent abdominal pain. ${ }^{10}$ However, there are no randomised controlled trials of ICBT for chronic musculoskeletal and other idiopathic pain syndromes. Also, the 13 randomised controlled trials that offered meta-analysable data rarely reported primary outcomes other than pain severity. There is little guidance on the putative role of ICBT in improving social, physical, and psychological functioning. ${ }^{9}$

This paper describes a residential interdisciplinary programme of cognitive behavioural therapy, incorporating physical therapy that was specifically designed for adolescents with long standing chronic pain and pain associated distress and disability. It was developed as a tertiary service at a national referral centre for chronic pain patients. Its effectiveness in changing parent and adolescent outcomes is reported. Guidance for treatment developments and trial design is discussed.

\section{METHODS}

\section{Design}

Patients were eligible for treatment if they were $11-18$ years old, had pain and pain associated disability of three months duration, and had an adult family member willing to participate. Exclusion criteria included: further treatment or assessment required (for example, if investigations for a potential disease related mechanism for pain were necessary) and/or significant psychopathology that required specific, separate intervention (for example, an eating disorder). All referrals were tertiary. All adolescents entering treatment completed a battery of measures prior to treatment, immediately following treatment, and at three months following treatment.

\section{Patients}

Seventy eight patients were assessed over a 24 month period. Patient and parent consent for assessment and treatment was given by all 78 dyads. Fifty seven entered and 56 completed treatment, and 43 returned at three months post-treatment. Of the 21 who did not enter treatment because of refusal or exclusion, the main reasons given were an inability to accept a self management approach $(n=5)$, further separate treatments required (for example, family therapy, referral to a paediatric oncologist) $(n=8)$, problems of access to hospital $(\mathrm{n}=5)$, and spontaneous improvement $(\mathrm{n}=3)$.

One patient who did not complete treatment left because of a new acute medical condition. Forty three patients returned to the three month follow up. Reasons for non-attendance were given by nine patients as difficulties in travelling $(n=5)$, pain $(n=1)$, other general illness $(n=2)$, and holiday $(\mathrm{n}=1)$. Four patients gave no reasons. Table 1 presents full biographical and clinical details of the sample.

\section{Measures}

Measurements were made in a number of areas for both the adolescents and their primary accompanying adult. 


\begin{tabular}{|c|c|}
\hline Female & 41 \\
\hline \multicolumn{2}{|l|}{ Age } \\
\hline Mean & 14.28 years \\
\hline SD (range) & $1.60(11-17)$ \\
\hline \multicolumn{2}{|l|}{ Accompanied by } \\
\hline Mother & $44(77.2 \%)$ \\
\hline Father or stepfather & $7(12.3 \%)$ \\
\hline Both parents & $3(5.3 \%)$ \\
\hline Grandmother & $3(5.3 \%)$ \\
\hline \multicolumn{2}{|l|}{ Adults at home } \\
\hline Father & $41(71.9 \%)$ \\
\hline Stepfather & $8(14.0 \%)$ \\
\hline Mother & $56(98.2 \%)$ \\
\hline \multicolumn{2}{|l|}{ Siblings } \\
\hline None & $8(14.0 \%)$ \\
\hline One & $31(54.4 \%)$ \\
\hline Two & $13(22.8 \%)$ \\
\hline Three & $4(7.0 \%)$ \\
\hline Four & $1(1.8 \%)$ \\
\hline \multicolumn{2}{|c|}{ Employment status of adults at home } \\
\hline Full time & $20(35.1 \%)$ \\
\hline Part time & $14(24.6 \%)$ \\
\hline Disabled & $6(10.5 \%)$ \\
\hline Homemaker & $10(17.5 \%)$ \\
\hline Student & $2(3.5 \%)$ \\
\hline Unemployed & $5(8.8)$ \\
\hline \multicolumn{2}{|l|}{ Diagnosis } \\
\hline Fibromyalgia & $9(15.8 \%)$ \\
\hline CRPS & $15(26.4 \%)$ \\
\hline Diffuse idiopathic pain & $14(24.6 \%)$ \\
\hline Localised idiopathic pain & $7(12.3 \%)$ \\
\hline Disease related & $8(14.0 \%)$ \\
\hline Headache & $1(1.7 \%)$ \\
\hline RAP & $2(3.5 \%)$ \\
\hline Renal pain & $1(1.7 \%)$ \\
\hline \multicolumn{2}{|l|}{ Onset } \\
\hline Sudden & $28(49.1 \%)$ \\
\hline Gradual & $23(40.4 \%)$ \\
\hline Unknown & $6(10.5 \%)$ \\
\hline \multicolumn{2}{|l|}{ Chronicity } \\
\hline Mean & 4.02 years \\
\hline SD (range) & $3.57(1-15)$ \\
\hline \multicolumn{2}{|l|}{ Frequency of pain } \\
\hline Persistent & $47(82.5 \%)$ \\
\hline Intermittent & $4(7.0 \%)$ \\
\hline Not known & $6(10.5 \%)$ \\
\hline \multicolumn{2}{|l|}{ Site of primary pain } \\
\hline Total body & $26(45.6 \%)$ \\
\hline Head & $1(1.7 \%)$ \\
\hline Limb & $15(26.4 \%)$ \\
\hline Back & $8(14.0 \%)$ \\
\hline Abdomen & $4(7.0 \%)$ \\
\hline Hip & 3 (5.3\%) \\
\hline
\end{tabular}

CRPS, complex regional pain disorder I; RAP, recurrent abdominal pain.

\section{Adolescent measures}

- Pain. Two continuous visual analogue scales of intensity (VAS) ${ }^{11}$ were used to measure current pain, and level of pain over the previous week.

- Anxiety. The Spence Children's Anxiety Scale (SCAS) ${ }^{12}$ provides an overall measure of anxiety and six subscales, each tapping a specific aspect of child anxiety. The scale has concurrent validity in relation to other child report measures of internalising problems (for example, the Child Depression Inventory $\left.(\mathrm{CDI})^{13}\right)$ and other measures of child anxiety.

- Catastrophic thinking about pain. The Pain Coping Questionnaire (PCQ) ${ }^{14}$ is a self report tool especially designed for young people in pain to measure which coping strategies they adopt. The catastrophic thinking subscale is particularly relevant to this population.
- Disability. The Functional Disability Inventory (FDI $)^{15}$ assesses independent living, taking into account the affect of pain on the child's everyday functioning and the caretaking burden on the family.

- Somatic awareness. The Modified Somatic Perception Questionnaire (MSPQ) ${ }^{16}$ is a 22 item measure of the frequency and breadth of diffuse somatic complaints. Although not standardised with adolescents, it is the closest available measure with adequate face validity for adolescents.

- Depression. The Children's Depression Inventory Short Form $(\mathrm{CDI})^{13}$ measures the severity of depressive symptoms. The age normed $\mathrm{T}$ scores above the 90th centile are considered clinically significant.

- Function. Two timed measures of function were used. First, time taken to walk a 10 metre distance, and second, the number of sit to stand movements completed within one minute.

- School attendance. Two measures of school attendance were calculated. First, the number of half day sessions (range l-10) attended in the previous school week were recorded. Second, seven categories of school attendance were also recorded (graduated, full time, part time ( $1-4$ sessions), part time (5-9 sessions), home tutoring, none, left having completed schooling).

\section{Adult measures}

Adult versions exist of the two pain VASs and the FDI, with adults responding to questions relating to their perceptions of their child's pain and disability respectively. Adults also completed the MSPQ based on their own experiences, and two further measures specific to adult affective distress were administered:

- The Hospital Anxiety and Depression Scale (HAD) ${ }^{17}$ is a brief affective measure designed to detect mood disorder in hospital populations. Scores over 8 for both anxiety and depression are considered clinically significant.

- The Parenting Stress Index (Short Form) ${ }^{18}$ is an instrument which screens for parents who are experiencing stressors that are consistently related to dysfunctional parenting. Scores over the 90th centile are considered clinically significant.

\section{Treatment team}

The treatment team included a paediatric rheumatologist, clinical psychologist, physiotherapist, occupational therapist, and a nurse. All had experience of rehabilitation of patients with pain and complex disability. The effectiveness of ICBT is critically dependent on a strong therapeutic alliance between patient and therapist and, to a lesser extent, a strong group alliance between patients. ${ }^{19}$ A process of clinical evidence testing was adopted within regular team meetings in which all team members provide observations of individual progress (or otherwise) which are tested against others' observations and consensual discussion. The clinical psychologist determined the speed and direction of therapy.

\section{Treatment}

Operant and cognitive behavioural principles were incorporated in all aspects of the treatment. A primary theme of the programme was the promotion of positive change despite pain, independence from medical and social care, and return to normal everyday adolescent activity. Therapy was informed from a number of sources. ${ }^{20-22}$ Overall treatment contact time was 110 hours (60 hours of physical and occupational activity; 35 hours of cognitive therapy, and 15 hours education). Over an 18 month period, seven programmes of six dyads and three programmes of five dyads were run. Each treatment session lasted 50 minutes. The day was structured as a school day from 
Table 2 Mean data (SD; SE) for 56 adolescents at pretreatment, post-treatment, and three months ( $\mathrm{n}=43$ ) following treatment

\begin{tabular}{|c|c|c|c|}
\hline Measures & Pretreatment & Post-treatment & Three months \\
\hline 1. Adolescent current pain (visual analogue scale) & $6.69(2.04 ; 0.27)$ & $6.91(2.01 ; 0.27)$ & $6.51(2.25 ; 0.34)$ \\
\hline 2. Adolescent week pain (visual analogue scale) & $7.03(1.40 ; 0.19)$ & $6.91(2.01 ; 0.27)$ & $6.68(2.03 ; 0.31)$ \\
\hline 3. Anxiety (Spence Child Anxiety Scale) & $33.60(15.93 ; 2.15)$ & $32.64(18.12 ; 2.49)$ & $27.48(13.44 ; 2.07)^{*} \dagger$ \\
\hline 4. Catastrophising (subscale of the Pain Coping Questionnaire) & $15.79(4.51 ; 0.6)$ & $15.39(4.52 ; 0.62)$ & $13.93(7.52 ; 0.74)^{*} \dagger$ \\
\hline 5. Disability (Functional Disability Index) & $34.25(6.94 ; 0.95)$ & $30.27(12.08 ; 1.63)^{*}$ & $29.32(12.33 ; 1.86)^{*}$ \\
\hline 6. Somatic awareness (modified Somatic Perceptions Questionnaire) & $17.07(9.77 ; 1.31)$ & $16.80(9.24 ; 1.26)$ & $11.93(7.83 ; 1.19)^{*}$ \\
\hline 7. Depression (Child Depression Inventory) & $59.93(13.64 ; 1.84)$ & $60.61(14.60 ; 1.99)$ & $58.80(13.87 ; 2.27)$ \\
\hline 8. Timed walk & $12.81(6.45 ; 0.91)$ & $10.20(5.19 ; 0.84)^{*}$ & $8.86(3.64 ; 0.69)^{*}$ \\
\hline 9. Stand-ups & $13.51(7.61 ; 1.06)$ & $17.04(8.81 ; 1.38)^{*}$ & $17.35(10.59 ; 2.08)$ \\
\hline
\end{tabular}

*Significant at $p<0.01$ compared with pretreatment data.

$\dagger$ Significant at $p<0.01$ compared with post-treatment data.

Table 3 Mean data (SD; SE) for 56 accompanying adults at pretreatment, post-treatment, and three months $(n=43)$ following treatment

\begin{tabular}{llll}
\hline Parents & Pretreatment & Post-treatment & Three months \\
\hline 1. Adolescent current pain (visual analogue scale) & $6.27(1.62 ; 0.23)$ & $6.33(2.15 ; 0.24)$ & $5.76(2.73 ; 0.41)$ \\
2. Adolescent week pain (visual analogue scale) & $6.29(1.73 ; 0.24)$ & $6.63(1.51 ; 0.29)$ & $5.97(2.5 ; 0.39)$ \\
3. Adolescent (Functional Disability Index) & $33.53(7.07 ; 0.95)$ & $28.07(10.22 ; 1.4)^{*}$ & $29.32(12.33 ; 1.94)^{*}$ \\
4. Parenting stress (Parental Stress Index-Total) & $73.44(26.01 ; 3.54)$ & $61.94(33.80 ; 4.6)^{*}$ & $59.02(34.87 ; 5.45)^{*}$ \\
5. Adult somatic awareness (Modified Somatic Perceptions) & $8.00(7.06 ; 1.02)$ & $7.22(6.2 ; 0.84)$ & $5.11(5.0 ; 0.78)^{*}$ \\
6. Depression (HAD) (Hospital Depression Index) & $6.74(3.29 ; 0.43)$ & $5.55(3.10 ; 0.42)^{*}$ & $5.33(3.75 ; 0.57)^{*}$ \\
7. Anxiety (HAD) (Hospital Anxiety Index) & $9.53(4.62 ; 0.61)$ & $7.62(4.12 ; 0.56)^{*}$ & $7.36(4.01 ; 0.62)^{*}$ \\
\hline * Significant at $p<0.01$ compared with pretreatment data. & & \\
\end{tabular}

900 am to $345 \mathrm{pm}$. Many sessions required evening or weekend written and skills practice homework. A rationale for therapy preceded each new treatment component. Emphasis was placed on normalisation, practice, and the maintenance and promotion of change at home. As the programme proceeded patients received written information about all aspects of the programme which built into a patient manual.

\section{Education}

Topics covered were: the physiology and anatomy of pain and exercise, the possible causes of chronic pain, the benefits of exercise, the consequences of chronic inactivity, and the benefits and side effects of medication in managing chronic pain.

\section{Activity}

Patients were encouraged to identify core daily exercises and activities. A baseline for each activity was calculated individually at $50 \%$ of the activity performed to tolerance. Daily activity targets were set at an approximate $20 \%$ daily increase over baseline and then over each previous day's activity. Baselines and the rate of increase were determined with staff. Praise was contingent specifically on achieving targets. The increase in all activities was paced using this approach.

\section{Cognitive therapy}

Specific sessions of family oriented cognitive therapy focused on fear related thinking and behaviour that involved the whole family, and also focused on somatic or illness relevant thinking. The adults attended group sessions without the adolescents, focusing on adaptation to living with a disabled child, managing health related anxiety, and skills in problem solving. Direct cognitive-behavioural coping skills were developed for each patient and were practised daily with monitored homework.

\section{RESULTS}

Related sample $t$ tests were used with a Bonferroni correction for repeated measurement. All significance levels were set at a corrected $\mathrm{p}<0.01$ and all confidence intervals are given at
95\%. Table 2 presents summary data for adolescents on all measures pre, post, and three months following treatment; table 3 presents summary data for the accompanying adults.

\section{Immediate treatment effects for adolescents}

There were significant increases in both timed measures of function and in the adolescents' reports of their own disability. Adolescents improved how fast they could walk 10 metres from 12.81 seconds to 10.20 seconds (mean difference of 2.61 seconds (95\% CI 1.02 to 4.2 ); SE 0.786 ), the number of standups performed in one minute from 13.51 to 17.04 (mean difference of 3.22 (0.79 to 5.65); SE 1.2), and self report of disability (mean difference 3.37 (0.65 to 6.09); SE 1.36).

\section{Three month treatment effects for adolescents}

Compared with pretreatment data there were statistically significant positive effects of treatment on anxiety (mean difference 6.35 (2.33 to 10.37); SE 1.99), catastrophic thinking about pain (mean difference 1.7 (0.72 to 2.67); SE 0.48), disability (mean difference 4.30 (1.44 to 7.17); SE 1.42), and somatic awareness (mean difference 4.43 (1.53 to 7.33); SE 1.27). Adolescents maintained the improvements on how fast they could walk 10 metres from 12.81 seconds to 8.86 seconds (mean difference 1.19 (0.23 to 2.15); SE 0.47). Compared with post-treatment data, there were statistically significant effects on anxiety (mean difference score 5.65 (2.25 to 9.05); SE 1.68 ), catastrophic thinking about pain (mean difference score 2.05 ( 1.0 to 3.11); SE 0.52) and somatic awareness (mean difference score 5.29 (3.12 to 7.44); SE 1.07).

\section{Immediate treatment effects for accompanying adults} There was a statistically significant increase in the adult perception of adolescent function (FDI adult: mean difference 4.43 (2.17 to 6.70); SE 1.13). There were statistically significant improvements in adult anxiety (mean difference 1.73 (0.54 to 2.92); SE 0.59), adult depression (mean difference 1.16 (0.34 to 1.98$)$; SE 0.41 ), and adult parental stress (mean difference 10.81 (2.91 to 18.71); SE 3.93). 


\begin{tabular}{|c|c|c|}
\hline & \multicolumn{2}{|c|}{ Change in category of schooling for 56 patients } \\
\hline & Pretreatment & $\begin{array}{l}\text { Three months } \\
\text { post-treatmentt }\end{array}$ \\
\hline Mean (SD; SE) number of sessions $(0-10)(n=56)$ & $4.75(3.70 ; 0.49)$ & $6.71(3.78 ; 0.50)^{*}$ \\
\hline Mean (SD; SE) sessions attended (0-10) $(n=42)$ & $3.28(2.56 ; 0.48)$ & $5.69(3.84 ; 0.48)^{*}$ \\
\hline \multicolumn{3}{|l|}{ Category of schooling $\dagger$} \\
\hline Full time & 14 & 29 \\
\hline Part time (>5 sessions) & 11 & 7 \\
\hline Part time $(<5$ sessions $)$ & 6 & 11 \\
\hline No school & 12 & 1 \\
\hline Left school & 1 & 1 \\
\hline Hospital school & 4 & 0 \\
\hline Home tutor & 8 & 7 \\
\hline
\end{tabular}

Three month treatment effects for accompanying adults Compared with pretreatment data adults continued to report a statistically significant change in their perception of adolescent function (mean difference 3.57 (0.27 to 6.87); SE 1.63), and the adult self reported data continued to show statistically significant improvement. There were statistically significant improvements in adult anxiety (mean difference score 2.12 (0.87 to 3.36); SE 0.62), depression (mean difference score 1.35 (0.31 to 2.39); SE 0.52) and adult parental stress (mean difference score 11.50 (0.58 to 22.42); SE 5.4). In addition, there was a statistically significant effect of treatment on somatic awareness compared with pretreatment data (mean difference 2.52 (0.7 to 4.3); SE 0.9). There were no significant changes in scores between post-treatment and three months following treatment.

\section{Return to school at three months}

Prior to treatment, only 14 adolescents were in full time education; three months following treatment 29 were attending full time education. Of the 14 in full time education pretreatment, one had graduated and one worsened. Therefore at three months following treatment 12 of the 29 patients had remained in full time education and 17 patients had returned to full time education. Prior to treatment 12 adolescents were receiving no formal education; at three months following treatment only one adolescent was still not receiving any formal education. Table 4 gives full details. Of the 42 patients whose category of schooling could have improved, 27 improved at least one category of schooling ( $\chi^{2}$ 17.71, $\mathrm{p}<0.001), 12$ remained the same, and three had worsened by one category. Of the 42 whose school attendance could have improved, the number of sessions attended increased significantly from a mean of 3.28 to 5.69 (mean difference score 2.41 ( 1.13 to 3.69); SE 0.42). The conservative test of the effect of treatment overall is to include all 56 patients (including the 14 at optimal level). This was also statistically significant (mean difference score 1.97 ( 1.0 to 3.0); SE 0.48).

\section{DISCUSSION}

Adolescent chronic pain and disability are notoriously unresponsive to unimodal and unidisciplinary treatments. An interdisciplinary team working within a cognitive behavioural framework is a promising area for development. Although the outcomes of this effectiveness study were broadly positive the study raises issues for further discussion.
First, the finding that adolescents do not report changes on many of the self report measures immediately postprogramme is intriguing. Some of the reasons may be methodological because measures used have been developed based on normal routines situated in home environments. ${ }^{15}$ However, this is not true for all of the measurement instruments. It may be simply unrealistic to expect adolescents to adjust quickly within three weeks on some of the affective measures, or it may be that treatment was only effective for changing physical outcomes.

Second, the exact process of therapeutic change in ICBT is unknown: in particular, how changes in one class of outcomes affect changes in another class of outcome. Only recently have the methods for such "process of therapy" studies been developed in chronic pain research. ${ }^{23}$ Also of interest is how parental variables affect adolescent variables. For example, a recent study of depression in chronically ill children found that child pain and maternal depression ${ }^{24}$ could predict child depression. In future studies with larger numbers of patients and adults it will be important to test the hypothesis that immediate posttreatment changes in parental affect have a mediating role for adolescent outcomes measured at three months, in particular school attendance.

Finally, although this is the first study of ICBT and adolescent chronic pain with a large enough sample to enable robust statistical analyses of treatment effects, there is no substitute for well designed and executed randomised controlled trials. ${ }^{9}$ Without a credible treatment comparison group we are not able to control for any non-specific effects of treatment setting, staff-patient relationships, or changes from normal environments. Although there are significant practical barriers to a successful trial, these are surmountable with multicentre collaboration. This study provides guidance on treatment content, delivery, and measurement.

\section{Conclusion}

An interdisciplinary cognitive behavioural programme of rehabilitation was effective in increasing physical performance, reducing emotional distress, increasing attendance in educational programmes, and returning adolescents to school. ICBT for the management of chronic musculoskeletal pain in adolescents is a very promising treatment urgently requiring multicentre collaboration to deliver a randomised controlled trial. 


\section{Authors' affiliations}

C Eccleston, J Clinch, H Connell, C Sourbut, Pain Management Unit, University of Bath and The Royal National Hospital for Rheumatic

Diseases, Bath, UK

P N Malleson, Division of Pediatric Rheumatology, Department of

Pediatrics, University of British Columbia, Vancouver, Canada

\section{REFERENCES}

1 Fearon I, McGrath PJ, Achat H. Booboos: the study of everyday pain among young children. Pain 1996;68:55-62.

2 Goodman JE, McGrath PJ. The epidemiology of pain in children and adolescents: a review. Pain 1991;46:247-64.

3 Perquin CW, Hazebroek-Kampscheur AAJM, Hunfeld JAM, et al. Pain in children and adolescents: a common experience. Pain 2000:87:51-8.

4 Perquin CW, Hazebroek-Kampscheur AAM, Hunfeld JAM, et al. Chronic pain among children and adolescents: physician consultation and medication use. Clin J Pain 2001;16;229-35

5 Malleson PN, Connell H, Bennett SM, et al. Chronic musculoskeletal and other idiopathic pain syndromes. Arch Dis Child 2001:84:189-92.

6 Morley S, Eccleston C, Williams, AC de C. Systematic review and meta-analysis of randomized controlled trials of cognitive behaviour therapy for chronic pain in adults, excluding headache. Pain 1999;80:1-13.

7 Kazdin AE, Weisz JR. Identifying and developing empirically supported child and adolescent treatments. J Consult Clin Psychol 1998;66:19-36.

8 Kibby MY, Tyc VL, Mulhern RK. Effectiveness of psychological interventions for children and adolescents with chronic medical illness: a meta-analysis. Clin Psychol Rev 1998;18:103-17.

9 Eccleston C, Morley S, Williams AC de C, et al. Systematic review of randomised controlled trials of psychological therapy for chronic pain in children and adolescents, with a subset meta-analysis of pain relief. Pain 2002;99:157-65.

10 Sanders MR, Shepherd RW, Cleghorn G, et al. The treatment of recurrent abdominal pain in children: a controlled comparison of cognitive behavioral family intervention and standard pediatric care. J Consult Clin Psychol 1994;62:306-14.

11 Varni JW, Thompson KL, Hanson, V. The Varni/Thompson Pediatric Pain Questionnaire. 1. Chronic musculoskeletal pain in juvenile rheumatoid arthritis. Pain 1987;28:27-38.

12 Spence SH. A measure of anxiety symptoms among children. Behav Res Ther 1998;36:545-66.

13 Kovaks $M$. Rating scales to assess depression in school aged children. Acta Paedopsychiatr 1981:46:305-15.

14 Reid GJ, Gilbert CA, McGrath PJ. The Pain Coping Questionnaire: a preliminary validation. Pain 1998;76:83-96.

15 Walker LS, Greene JW. The Functional Disability Inventory: measuring a neglected dimension of child health status. J Pediatr Psychol $1991: 16: 39-58$

16 Main CJ. The Modified Somatic Perceptions Questionnaire. J Psychosom Res 1983;27:503-14

17 Zigmond AS, Snaith RP. The Hospital Anxiety and Depression Scale. Acta Psychiatr Scand 1983;67:361-70.

18 Abidin RR. Parenting Stress Index. Psychological Assessment Resources, Florida, Odessa, 1995.

19 Roth A, Fonagy P. What works for whom: a critical review of psychotherapy research. New York: Guildford Press, 1996.

20 Fordyce WE, Fowler RS, Lehmann JF, et al. Some implications of learning in problems of chronic pain. J Chron Dis 1968;21:179-90.

21 Bursch B, Walco GA, Zeltzer L. Clinical assessment and management of chronic pain and pain associated disability syndrome (PADS). J Dev Behav Pediatr 1998;19:45-53.

22 McGrath PJ, Finley GA, eds. Chronic and recurrent pain in children and adolescents. Seattle: IASP Press, 1999.

23 McCracken L, Gross R, Eccleston C. Multimethod assessment of treatment process in chronic low back pain: comparison of reported pain related anxiety with directly measured physical capacity. Behav Res Ther 2002;40:585-94

24 Williamson GM, Walters AS, Shaffer DR. Caregiver models of self and others, coping, and depression: predictors of depression in children with chronic pain. Health Psychol 2002;21:405-10. 